\title{
Investigating the Impact of Learners Emotions on Academic Performance and Motivation Using Ethnography
}

\author{
Shakirat Abimbola Adesola and Yongmin Li
}

\begin{abstract}
Researches has shown that students experience a wide range of emotions in class and while doing test and this thus have consequences on learning and achievement. This research therefore tried to find out the effect of achievement pressure and expectation of failure on students'. Students' motivation and academic performance were examined with a sample of twenty-four students of Computer Science in 200 level. The results of the investigation revealed that students' motivation and action are settings to consider when investigating the different types of emotions students experience while in class and doing test. The results also revealed that there is significant difference between class-related emotions and test-related emotions on students' hypotheses for patterns within and between domains.
\end{abstract}

Index Terms-Academic performance, emotions, ethnography and motivation.

\section{INTRODUCTION}

Emotions can be defined as, "states elicited by rewards and punishments, including changes in rewards and punishments [1]. Emotions are also defined as complex phenomena that include affective, cognitive, physiological, motivational, and expressive components [2]. People work to get reward, while people try to avoid punishment. Emotion is then an on and off switch for learning, emotional brain, the limbic system, has the power to open or close access to learning, memory, and the ability to make connections. Ref [3] stated that emotions are phases of an individual's intuitive appraisal either of his own organismic states and urges to act or of the succession of environmental situations in which he finds himself.

The classroom is an emotional place. Students often experience emotions in classroom settings. For example, students can be happy during studying, confidence for success, feel pride in their achievement, and be amazed at discovery a new solution, experiences nervousness about failing examinations, feels embarrassed over low scores or be bored during teachings.

\section{PROCEDURE FOR PAPER SUBMISSION}

Some may even bring personal emotions that are linked

Manuscript received April 22, 2018; revised May 31, 2018.

Shakirat Abimbola Adesola is with the Department of Computer Science, Brunel University London, United Kingdom. She is on leave from Federal College of Education (Special), Oyo, Nigeria (e-mail: Shakirat.Adesola@brunel.ac.uk).

Yongmin $\mathrm{Li}$ is with the Department of Computer Science, Brunel University London, United Kingdom (e-mail: Yongmin.Li@brunel.ac.uk). with events outside the school, but which also have effects on their learning.

There are broadly two categories of emotions by [4], the positive emotions which comprises of relief, hope and pride, and the negative emotions that includes anxiety, angry and sadness. Positive emotions tend to induce cognitive resources and focus attention on the learning task, support interest and intrinsic motivation, and facilitate deep learning. Thus, these emotions are expected to positively influence student's academic achievement under most task conditions [5].

Achievement emotions have a great impact on how learners relate with present and future learning and performance tasks. Such tasks include goals, strategy use, and persistence [6]-[8]. Furthermore, emotions experience in class session form resulting behaviours, goals, and emotions [8]. Because of the instant and continuing effect of emotions on learning and achievement, it is important that pedagogical training that maintains adaptive students' emotions for effective teaching and learning be understood.

\section{BACKGROUND}

Learning environment settings abound with emotions like enjoyment, hope, anxiety, anger, hopelessness, pride, boredom or shame. These emotions are crucial for students' motivation, learning, performance, identity development, and health [9].

Various researches as shown that students experience lots of emotions in academic settings [10]. It was revealed in [4] that academic emotions are significantly related to student motivation, learning strategies, cognitive resources, self-regulation and academic achievement. The causes and the types of emotions also vary with situations. Thus, learning circumstances prompt diverse self-referenced, task-related and social emotions.

Ref [11] discovered that, there were no significant difference in students' performance with variation in the mode of teaching and learning. He argues that, "individual differences in learning styles dictate that technology will facilitate learning for some, but will probably inhibit learning for others". Ref [12] argues that technology, resources efficiency, policy and pedagogy, with little exploration of the student experience and the implications of that. Also, [4] found out that emotions influence learning and achievement, mediated by attention, self-regulation, and motivation. This can thus guide the learners toward or away from learning matters in learning situations [13]. Students perceived self-regulation correlates positively with positive emotions, whereas perceived external regulation correlates with negative emotions [4]. Positive emotions thus facilitate 
self-regulated learning [14], [15]. Emotions, for instance interest, on the other hand enable actions that provide novelty or challenge, and are closely correlated to all self-determined activity [16].

\section{A. Motivation in Learning}

Motivation is a process where goal directed activities begin and then eventually are sustained. Achievement motivation is commonly focused on studied in educational setting. Achievement motivation is enacted when an individual strives to be competent [17]. A related construct is Brophy's "motivation to learn," which is describes as more than doing the bare minimum to meet the requirements, but deliberately engaging in academic tasks with the intent to acquire new knowledge or skills [18]. Early theorists suggested that achievement motivation is caused by instincts, traits, needs, or drives [19]. It was noted that distinctive characteristics of a person determines achievement motivation need or trait. It was believed that students who have more of the achievement trait or drive will be more motivated towards success. Students has to adapt to their emotional and cognitive request and conflicts as well as social settings and environmental cues [20]. This implies that students need to adjust their cognitive, motivational and emotional learning process [14], [21]-[23].

\section{B. Test Anxiety}

Emotionality is the individual's subjective awareness of the heightened autonomic arousal rather than the arousal itself [24]. Researches have shown that high emotionality is associated with declining performance only when the individual is also experiencing high levels of worry [25], [24]. It was also revealed that high levels of emotionality negatively stimulus test performance only under circumstances where the individual also experienced high level of worry, signifying that worry is the primary performance predictor [26]. Therefore, high level self-confidence regarding test performance is attributed to high level of emotionality. However, test anxiety has been attributed to behavioural phenomenon because this can modify and reduce test anxiety when emotionality component is targeted. This implies that student experience test anxiety when there is rise in levels of physiological arousal.

Cognitive test anxiety consists of individuals' cognitive reactions to evaluate situations, or internal dialogue regarding evaluative situations, before, during and after assessing the tasks [27]. Individuals with high levels of test anxiety usually have issues on extreme worry over assessment; comparing others performance with themselves; low levels of confidence in performance; consequences of failures; unprepared for assessment and loss of self-esteem [25]-[27]. Path analyses have also confirmed that cognitive test anxiety had the strongest connection with performance.

\section{Research Questions}

Lots of research has been done on teaching and learning in higher institutions with emphasis on the impact on institutions and students. Many of the researches were teacher-oriented and not students-oriented. This research therefore intends to find a gap in the experience of learners while trying to answer the following research questions. Learners self-reported emotions would form three clusters: a positive, a negative and a low emotions cluster. This research therefore intends to find out if learners can be grouped according to the emotions experiences during class and test; the relationship between emotions groups and performance; correlation between class-related emotions and test-related emotions and answer the following questions:

1) Do achievement pressure and expectation of failure act as contributors to students' thought and action.

2) Do test anxiety correlates with academic performance?

3) Do negative emotions affect students' thought, motivation and action?

\section{METHODS}

Ethnography encompass the researcher take part in events, observing activities, taking notes and gathering unformed data to generate an interpretation of the circumstances being studied (perhaps in a school or university rather than a little-known [28]. A wide range of options such as, audio or video recording can be used to record events using ethnography in academic environment that can be useful to the pedagogic researchers. This is because recordings improve correctness, in that it is likely to have a more or less record of what was said, but may increase the investigator's load, particularly if an expert typist is not present to write [28]. Ref [29] used a "Quick and Dirty" ethnography to collect emotional data in a cognition and emotion support e-learning research, but stated that there is a trade-off between the efficiency and completeness in the method.

\section{A. Participants}

Participants were twenty-four 200 Level students of Computer Science department, Federal College of Education (Special), Oyo, Nigeria comprising of 10 females representing $41.7 \%$ and 14 males representing $58.31 \%$. Participants were randomly selected, and aged between 16 and 27. Mean age 23.5. Three were Hearing impaired representing $12.5 \%$. Participants consent was sought before the class and they all agreed to take part in the research. They were also told that their responses in the questionnaire will be anonymous and used purposely for research.

\section{B. Learning Environment}

Participants were taught in two Computer Science topics and video recording of the class session were taken. A test was conduct after each class session and marked to obtain participants achievement. Also, an interview session was conducted after each class session where the video recording was played and each of the participants were interviewed on the emotions experience during the class. Finally, questionnaire was distributed to each of the participant for further clarification.

\section{Experimental Procedures}

The main procedures in this research are listed below:

1) Consultations with students to give details of the research aims and procedure.

2) Distributing consent form to all of them to fill to seek 
their approval.

3) Teacher strategies the lesson plans with the research team.

4) Introduce the study guide to the students.

5) Teaching the lesson and video recording of the class session.

6) After the class sessions as ended, the teacher gives test to the students.

7) The teacher and students interact to review the video to recall any emotions recognised.

8) Questionnaires were later distributed to students to obtain additional information.

\section{MEAsures}

The Achievement Emotions Questionnaire was used to measure the emotions learners experienced during class, before and after test. A total of 54 items measure boredom, hopelessness, angry, anxiety, enjoyment and pride for class-related emotions, while relief, hopelessness, angry, anxiety enjoyment and pride were also considered for test-related emotions. Boredom was replaced with relief in test-related emotions. Opinions were measured using a 5-point Likert scale rating of 1 for Strongly Disagreed and 5 for Strongly Agreed. Cronbach's Alpha: .80 was achieved; Cronbach's Alpha based on standardized items: .77 using standardized items 53.

Three types of measures were used for evaluating the class session: (a) AEQ questionnaire, (b) interview after class session, and (c) grade of test. Students' achievement was measure through the grade obtained in the test administered after the class session.

\section{A. Achievement Pressure and Expectation of Failure}

Achievement pressure and expectation of failure was measured with anxiety questions items $(N=4)$ for class-related and $(N=4)$ for test-related. All the achievement pressure and expectation of failure items were extracted from the 53 AEQ questionnaire items used for the research. Cronbach's alphas for this study's samples yielded .82 for standardized items 53.

\section{B. Students' Thought, Motivation and Action}

Student's thought and action for class-related were measured by hopelessness $(N=4)$, bored $(N=4)$, angry $(N=4)$; and hopelessness $(N=4)$, relief $(N=4)$, angry $(N=4)$ for test-related. Motivation was measured by excitement and motivated goals orientation $(N=4)$ for class-related and by $(N=4)$ for test-related. The motivation items were from the AEQ questionnaire items. Cronbach's alpha with the 53 standardized items used was .80. Five-point Likert scales rating of 1 for Strongly Disagreed to 5 for Strongly Agreed was used.

\section{Academic Performance}

Academic performance was measured by the marks obtained in the two tests conducted. Average of the tests was use to get the correlation for the emotions.

\section{MEASURES AND ANALYSIS ACHIEVEMENT}

\section{A. Results}

Several statistical tests in the Statistical Package for the Social Sciences (SPSS) were run for the study including the ANOVA, descriptive statistics, regression, reliability and correlations tests. IBM SPSS statistics 20 was used to conduct the analysis. The prediction of directional relationship within settings was tested using the Pearson's two-tailed correlations for each of the emotions within each academic domain. Positive emotions were found to be mostly correlated with one another, while the negative emotions were generally positively correlated with one another.

TABLE I: DESCRIPTIVE ANALYSIS OF CLASS-RELATED EMOTIONS

\begin{tabular}{|l|l|l|l|l|l|l|}
\hline Emotions & M & SD & Min & Max & Skewness \\
\hline Boredom & 7.59 & 4.00 & 1.00 & 4.50 & 4.87 & 3.96 \\
\hline Hopelessness & 7.75 & 4.74 & 1.00 & 4.25 & 5.27 & -0.95 \\
\hline Angry & 6.96 & 3.83 & 1.00 & 4.25 & 5.47 & 1.33 \\
\hline Anxiety & 10.50 & 5.19 & 1.00 & 5.00 & -5.89 & -3.85 \\
\hline Enjoyment & 16.17 & 5.08 & 1.00 & 5.00 & -58 & \\
\hline Pride & 16.04 & 4.29 & 1.50 & 5.00 & -4.83 & \\
\hline
\end{tabular}

TABLE II: DESCRIPTIVE ANALYSIS OF TEST-RELATED EMOTIONS

\begin{tabular}{|c|c|c|c|c|c|c|}
\hline Emotions & M & SD & Min & Max & Skewness & Kurtosis \\
\hline Relief & 14.08 & 9.27 & 1.00 & 5.00 & -2.34 & 2.10 \\
\hline Hopelessness & 7.66 & 4.57 & 1.00 & 4.50 & 4.09 & 0.49 \\
\hline Angry & 9.16 & 4.68 & 1.00 & 4.50 & 2.32 & 0.49 \\
\hline Anxiety & 11.34 & 5.36 & 1.00 & 5.00 & 0.41 & -2.89 \\
\hline Enjoyment & 14.88 & 4.69 & 1.00 & 5.00 & -3.68 & 0.78 \\
\hline Pride & 15.45 & 4.53 & 1.00 & 5.00 & -4.28 & 3.36 \\
\hline
\end{tabular}

Descriptive analysis was performed on the items of the questionnaires on the emotions. There was high mean intensity in positive emotions of pride with $\mathrm{M}=16.04$ and enjoyment with $\mathrm{M}=16.17$. Negative emotions were relatively low with boredom having $\mathrm{M}=7.59$, Hopelessness with $\mathrm{M}=7.75$, angry with $\mathrm{M}=6.96$. However, anxiety was on the high side with $\mathrm{M}=10.50$ as shown in Table $\mathrm{I}$.
Descriptive analysis performed on the items of the questionnaires on Test-related emotions revealed there were also high mean intensity in positive emotions but slightly lower than that of class-related emotions. Test-related pride with $\mathrm{M}=15.45$ and enjoyment with $\mathrm{M}=14.88$. This might be because of low levels of confidence in performance. However, Boredom was replaced with Relief in test-related 
emotions and recorded high intensity with $\mathrm{M}=14.08$ in Table II. Negative emotions have low mean intensity, hopelessness having $\mathrm{M}=7.66$, almost the same as class-related of $M=7.75$. Angry was higher for test-related with $\mathrm{M}=9.16$ compared with class-related of $M=6.96$. This might be because of consequence of failures. Anxiety also increased in intensity from 10.50 for class-related emotions to 11.34 for test-related emotions. This could be because of extreme worry over assessment, unprepared for the test or loss of self-esteem.

\section{B. Results: Pearson's Correlation}

One-way ANOVA was performed to compare the means. Correlation of the bivariate was conducted to obtain the Pearson's two-tailed test of significance. Positive emotions were positively correlated with one another while negative emotions were negatively correlated with each other as shown in Table III. Enjoyment and pride scale correlation recorded the highest at Pearson's $r=.63$, followed by hopelessness and angry with $r=.42$. Boredom and hopelessness were also positively correlated at $r=.31$.

TABLE III: CLASS-RELATED EMOTIONS WITHIN DOMAINS

\begin{tabular}{|l|l|l|l|l|l|l|}
\hline Emotions & Boredom & Hopelessness & Angry & Anxiety & Enjoyment & Pride \\
\hline Boredom & - & $.31^{*}$ & .18 & -.07 & $-.34^{*}$ & -0.21 \\
\hline Hopelessness & - & - & $.42^{*}$ & .24 & $-.39^{*}$ & $-0.34^{*}$ \\
\hline Angry & - & - & - & -27 & -.22 & -0.07 \\
\hline Anxiety & - & - & - & - & -.13 & -0.07 \\
\hline Enjoyment & - & - & - & - & - & $-0.63^{*}$ \\
\hline Pride & - & - & - & - & - \\
\hline
\end{tabular}

TABLE IV: TEST-RELATED EMOTIONS WITHIN DOMAINS

\begin{tabular}{|l|l|l|l|l|l|l|}
\hline Emotions & Relief & Hopelessness & Angry & Anxiety & Enjoyment & Pride \\
\hline Relief & - & .15 & -.04 & .23 & .17 & 0.17 \\
\hline Hopelessness & - & - & $.37^{*}$ & .11 & -.23 & $-0.35^{*}$ \\
\hline Angry & - & - & - & .13 & -.22 & $-0.35^{*}$ \\
\hline Anxiety & - & - & - & - & -.05 & -0.09 \\
\hline Enjoyment & - & - & - & - & - & $0.72^{*}$ \\
\hline Pride & - & - & - & - & - & - \\
\hline
\end{tabular}

This result revealed that achievement pressure and expectation of failure do act as contributors to students' thought and action. Boredom and enjoyment were negatively correlated having $r=-.34$; hopelessness and enjoyment $r=$ -.39. However, within domain correlation in test-related emotions were higher for positive emotions. Enjoyment scale with pride was higher with $r=.72$ as indicated in Table IV; hopelessness with anger has $r=.37$; hopelessness was negatively correlated with pride at $r=-.35$, having the same correlation with angry also at $r=-.35$. This might be due to issues of worry.

A one-way ANOVA was also performed to find out whether achievement pressure and expectations of failure could act as contributors to students' thought and action. Levene's test measured by anxiety questions items revealed $\mathrm{F}(1,22)=3.566, \mathrm{p}=.616$ showed that achievement pressure and expectations of failure do act as contributors to students' thought and action. This was collaborated with class-related anxiety with $\mathrm{F}(1,22)=5.654, \mathrm{p}=.531$ lower than test-related anxiety. Students' thought and action that was measured by hopelessness, boredom, angry and relief were both also significant. Relief from test was high with $\mathrm{F}(1,22)=10.523$, $\mathrm{p}=.338$, while hopelessness and angry had $\mathrm{F}(1,22)=13.061$, $\mathrm{p}=.253$ and $13.464, \mathrm{p}=.248$ respectively. This might be as a result of uncertainty over the test results. It might also be as a result of fact that test anxiety consists of personal cognitive reactions to evaluate situations, or internal interchange regarding measuring situations, before, during and after assessment.

Test-related and class-related emotions recorded different intensity for all the emotions. Within correlation setting for the class-related and test-related were in a wide margin range.
This implies that there is significant difference between class-related emotions and test-related emotions. This suggest that test-related emotions and class-related emotions does not stimulate each other and did not form positive feedback loops in the environment-appraisal-emotions-achievement outcome cycle. This also implies that learners can be grouped according to emotions experiences during class and assessment.

A regression analysis was performed to predict test performance with anxiety emotions. The results as presented in Table $\mathrm{V}$ revealed that performance with predictor test 1 , Beta $=0.523$ and 0.610 for test 2 , both at $p<.001$. A within-setting repeated ANOVA was performed to assess the hypothesis that test anxiety correlates positively with academic performance. Pairwise comparisons with a Bonferroni adjustment for Equal Variance Assumed were done to find where the precise mean differences occurred. Bonferroni's Equal Variance Assumed was used because it controls the overall type I error rate and assumed that overall rate does not exceed 0.05 . It is also more powerful when the numbers of comparisons are few as in this study. The significant levels for the ANOVA were also high at 0.606 for test 1 and 0.738 for test 2 . This clearly showed that test anxiety correlate significantly with academic performance.

\section{DISCUSSION}

Results from the research had revealed that test anxiety do correlate significantly with academic performance. This suggests that when students experience achievement pressures, this will induce emotional arousal. This result is in line with [7] control-value theory of achievement emotions, 
that positive emotions create positive feedback loops for the environment-appraisal-emotions-achievement outcome cycle. This is also agreement with [26] which stated that high levels of emotionality negatively stimulate test performance when individual experience high level of worry as the main performance indicator.

This is also because anxiety caused by achievement pressure and expectations of failure can be a motivating or demotivating emotion depending on the situation, in this case, arousing feelings of hopelessness and anxiety. This was also in line with cognitive interference model which suggest that individuals with high levels of test anxiety perform poorly in large due to an inability to suppress competing thoughts during the exam. Individuals with high test anxiety are more likely to worry about the outcomes of the test, comparing themselves with others and think more on their inability to prepare well for the test [24].

TABLE V: STEPWISE REGRESSION ANALYSIS PREDICTING TEST PERFORMANCE WITH TEST ANXIETY

\begin{tabular}{|c|c|c|c|c|c|}
\hline \begin{tabular}{c} 
Test\} $\\
{\text { Variable }}$ & B & SE B & $\beta$ & $t$ & Sig. \\
\hline $\begin{array}{l}\text { Test } 1 \backslash \\
\text { Anxiety }\end{array}$ & -0.499 & 2.702 & -0.113 & -0.295 & 0.523 \\
\hline $\begin{array}{l}\text { Test } 2 \backslash \\
\text { Anxiety }\end{array}$ & -0.224 & 2.557 & -0.018 & -0.091 & 0.610 \\
\hline
\end{tabular}
\end{tabular}

The results of the study show that learners with positive emotions have higher significant performance achievement than learners with negative emotions. This was revealed through enjoyment and pride correlating positively and having high intensity. Hopelessness have almost the same intensity at class and during test. This might be due to the fact that thinking about how to answer questions in the test alone can cause anxiety. This implies that emotions do affect students' thought, motivation and action.

\section{CONCLUSION}

Findings from this study revealed that students' motivation and action are settings to consider when investigating the different types of emotions students experience while in class and while doing test. The overall outline for the domain-specific emotions revealed that students experienced positive emotions more often that negative emotions across domains. They however experience feelings of hopelessness more often that boredom and angry. This means that students might feel frustrated in attempt to understand lectures or while answering questions during test.

Result of within and across domains settings supported the hypotheses as positive emotions were positively correlated with each other thereby forming a positive feedback. Also, negative emotions were positively correlated forming negative feedback, and this is in line with [24]. It was also discovered that test anxiety correlates significantly with academic performance suggesting that students with high level of anxiety arousal for test perform poorly in academic assessment. The results also show that class-related emotions and test-related emotions have different emotional effect on students which support hypotheses for patterns within and between domains.

\section{REFERENCES}

[1] E. T. Rolls, "On the brain and emotion," Behavioral and Brain Sciences, vol. 23 no. 2, pp. 219-228, 2000.

[2] V. Shuman and K. R. Scherer, "Concepts and structures of emotions," International handbook of emotions in education, pp. 13-35, 2014.

[3] J. Bowlby, "Attachment and loss," Basic Books, 1980.

[4] R. Pekrun, T. Goetz, W. Titz, and R.P. Perry, "Academic emotions in students' self-regulated learning and achievement: A program of qualitative and quantitative research," Educational Psychologist, vol. 37, no. 2, pp. 91-105, 2002.

[5] R. Pekrun, S. Lichtenfeld, H. W. Marsh, K. Murayama, and T. Goetz, "Achievement emotions and academic performance: Longitudinal models of reciprocal effects," Child Development, 2017.

[6] L. Linnenbrink-Garcia and M. M. Barger, "Achievement goals and emotions," International Handbook of Emotions in Education, pp. 142-161, 2014.

[7] R. Pekrun, "The control-value theory of achievement emotions: Assumptions, corollaries, and implications for educational research and practice," Educational Psychology Review, vol. 18 no. 4, pp. 315-341, 2006.

[8] R. Pekrun and R. P. Perry, "Control-value theory of achievement emotions," International Handbook of Emotions in Education, pp. 120-141, 2014.

[9] P. A. Schutz, D. I. Cross, J. Hong, and J. Osbon, "Teacher identities, beliefs, and goals related to emotions," Emotion in Education, pp. 223-242, 2007.

[10] P. A. Schutz and J. T. DeCuir, "Inquiry on emotions in education," Educational Psychologist, vol. 37 no. 2, pp. 125-134, 2002.

[11] T. L. Russell, "Technology wars: Winners and losers-The no significant difference phenomenon," Educom Review, vol. 32, pp. 44-47, 1997.

[12] P. S. Cookson, "Implications of Internet technologies for higher education: North American perspectives," Open Learning, vol. 15 no. 1, pp. $71-80,2000$.

[13] H. C. Ellis, "Resource allocation model of the effect of depressed mood states on memory," Affect, Cognition, and Social Behavior, 1988.

[14] M. Boekaerts, P. R. Pintrich, and M. Zeidner, Handbook of Self-regulation, Elsevier, 2005

[15] C. S. Carver and M. Scheier, "Principles of self-regulation: Action and emotion," Guilford Press, 1990.

[16] M. Gläser-Zikuda, S., Fuß, M. Laukenmann, K. Metz, C. Randler, "Promoting students' emotions and achievement-Instructional design and evaluation of the ECOLE-approach," Learning and Instruction, vol. 15 no. 5, pp. 481-495, 2005.

[17] A. J. Elliot and M. A. Church, "A hierarchical model of approach and avoidance achievement motivation," Journal of Personality and Social Psychology, vol. 72, no. 1, p. 218, 1997.

[18] G. Denzine and R. Brown, "Motivation to learn and achievement," Media Rich Instruction, Springer, Cham, June 2015.

[19] D. H. Schunk, P. R. Pintrich, and J. L. Meece, "Motivation in education: Theory, research and application," 3rd ed., Upper Saddle River, NJ: Merrill, 2008.

[20] S. Volet and S. Järvelä, "Motivation in learning contexts: Conceptual advances and methodological implications," Amsterdam, Elsevier, 2001.

[21] M. Boekaerts, "Self-regulated learning at the junction of cognition and motivation," European Psychologist, vol. 1, no. 2, pp. 100-112, 1996.

[22] P. H. Winne, "Self-regulated learning viewed from models of information processing," Self-regulated Learning and Academic Achievement: Theoretical Perspectives, vol. 2, pp. 153-189, 2001.

[23] B. J. Zimmerman, M. Boekarts, P. Pintrich, and M. Zeidner, "A social cognitive perspective," Handbook of Self-regulation, vol. 13 no. 1, pp. 695-716, 2000.

[24] R. Schwarzer, "Worry and emotionality as separate components in test anxiety," Applied Psychology, vol. 33 no. 2, pp. 205-220, 1984.

[25] L. W. Morris, M. A. Davis, and C. H. Hutchings, "Cognitive and emotional components of anxiety: Literature review and a revised worry-emotionality scale," Journal of Educational Psychology, vol. 73 no. 4 , p. $541,1981$.

[26] J. L. Deffenbacher, "Worry and emotionality in test anxiety," Test Anxiety: Theory, Research, and Applications, pp. 111-128, 1980.

[27] J. C. Cassady and R. E. Johnson, "Cognitive test anxiety and academic performance," Contemporary Educational Psychology, vol. 27, no. 2, pp. 270-295, 2002.

[28] D. R. Cotton, A. Stokes, and P. A. Cotton, "Using observational methods to research the student experience," Journal of Geography in Higher Education, vol. 34, no. 3, pp. 463-473, 2010. 
[29] X. Tao, Q. Niu, and M. Jackson, "Using an ethnographic approach to collect emotional data in affective learning research," International Journal of Information and Electronics Engineering, vol. 3 no. 2, p. 216, 2013.

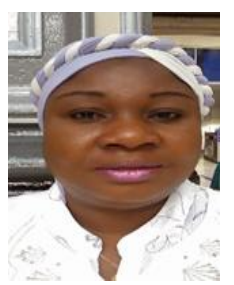

Shakirat Abimbola Adesola is a research student a the Department of Computer Science, Brunel University London, United Kingdom. She had her B.Sc. and M.Sc. from University of Ibadan, Nigeria. Her research area is in speech recognition and gender classification. She is on study leave from Federal College of Education (Special), Oyo, Nigeria.

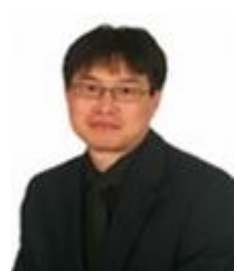

Yongmin $\mathbf{~ L i}$ is a senior lecturer with the Department of Computer Science, Brunel University London, United Kingdom. He received his PhD from Queen Mary, University of London, MEng and BEng from Tsinghua University, China. He is a senior member of the IEEE and also a fellow of the Higher Education Academy. He had worked with the British Telecom Laboratories before joining Brunel University, London. He had published many articles in high profile journals. His research area is in image processing. 